p-ISSN 0030-9311; e-ISSN 2338-476X; Vol.59, No.1(2019). p. 44-50; doi: http://dx.doi.org/10.14238/pi59.1.2019.44-50

Original Article

\title{
Predictors of early growth failure in preterm, very low birth weight infants during hospitalization
}

\author{
Noviyani Leksomono, Ekawaty L. Haksari, Retno Sutomo
}

\begin{abstract}
Background Preterm, very low birth weight (VLBW) infants experience intrauterine nutritional deficits and perinatal comorbidities that may impair early growth parameters. Early growth failure has detrimental effects on later growth and neurodevelopment in childhood.

Objective To analyze predictors of early growth failure in preterm, VLBW infants and differences in early growth parameters between small-for-gestational age (SGA) and appropriate-for-gestational age (AGA) infants.

Methods This retrospective cohort study was conducted at Dr. Sardjito Hospital, Yogyakarta from 2011 to 2016. Subjects were preterm infants, with birth weights of 1,000-1,499 g. Twins, those who died during hospitalization, were discharged against medical advice, or had incomplete medical records were excluded. Adequate intrauterine growth was determined by the Lubchenco table criteria. Growth parameters and perinatal comorbidities were collected from medical records. Growth failure was defined as discharge weight less than 10th percentile of the Fenton growth curve. Bivariate and multivariate analysis were used to analyze potential predictive factors of early growth failure.

Results Of 646 preterm, VLBW infants during the study period, 398 were excluded. Respiratory distress and SGA were predictors of early growth failure (AOR 6.94; 95\%CI 2.93 to 16.42 and $\mathrm{AOR} 34.44 ; 95 \% \mathrm{CI} 7.79$ to 152.4 , respectively). Mean weight velocities in SGA and AGA infants were not significantly different [16.5 (SD 5.9) and 17.5 (SD 5.3) g/ $\mathrm{kg} / \mathrm{day}$, respectively; $(\mathrm{P}=0.25)]$. Median time to regain, time to reach full feeding, and time to reach $120 \mathrm{kcal} / \mathrm{kg} /$ day were also not significantly different between SGA and AGA infants.

Conclusions SGA and respiratory distress are predictors of early growth failure in preterm, VLBW infants during hospitalization. The SGA infants grow slower than AGA infants. [Paediatr Indones. 2019;59:44-50; doi: http://dx.doi. org/10.14238/pi59.1.2019.44-50 ].
\end{abstract}

Keywords: SGA-AGA; growth failure; preterm; VLBW
1 $s$ the biggest proportion of the NICU population, preterm and VLBW infants are susceptible to perinatal comorbidities, as well as growth and neurodevelopmental impairment. ${ }^{1}$ About $4.7 \%$ of all births are VLBW infants, and Indonesia is included in the top ten nations with the highest prevalence of LBW (10.2\%). 2,3 Preterm, VLBW infants may be further described as either SGA or AGA. Most SGA infants experienced intrauterine growth restriction (IUGR) and nutritional deficits.4,5 Due to metabolic and gastrointestinal immaturity, compromised immune function, and other complicating medical conditions, nutritional deficits may continue during the early weeks after birth, impairing the growth rate. Perinatal comorbidities, such as patent ductus arteriosus (PDA), neonatal sepsis, necrotizing enterocolitis (NEC), respiratory distress, and anemia, aggravate the problem. Intrauterine chronic hypoxia in SGA infants results in maladaptation and ineffective energy utilization. Their thin, subcutaneous fat layer leads

From the Department of Child Health, Universitas Gadjah Mada Medical School/Dr. Sardjito General Hospital, Yogyakarta, Central Java, Indonesia.

Corresponding author: dr. Noviyani Leksomono, Department of Child Health, Universitas Gadjah Mada Medical School/Dr. Sardjito General Hospital. Jalan Kesehatan No.1, Sekip, Yogyakarta 55284, Indonesia. Telp. +62-274-561616; Email: noviyani_leksomono@yahoo.com.

Submitted December 19, 2018. Accepted February 15, 2019. 
to higher energy reserve loss and hypothermic stress leads to higher basal metabolic rates. ${ }^{5,6}$

The early postnatal growth target of preterm infants is to reach a growth rate similar to intrauterine growth at the same gestational age. ${ }^{7}$ Weight velocity, time to regain birth weight, time to reach full feeding, and time to reach $120 \mathrm{kcal} / \mathrm{kg} / \mathrm{day}$ are some growth parameters that may be impaired in the early weeks, resulting in growth failure, defined as a discharge weight $<10^{\text {th }}$ percentile according to Fenton growth charts by chronological age. 8,9 The incidence and predictors of early postnatal growth failure among preterm, VLBW infants have not been well studied in Indonesia. Early postnatal growth failure may affect long term neurodevelopmental outcomes and cause persistent growth failure. ${ }^{10,11}$ The aims of this study were to analyze potential predictive factors of early growth failure in the perinatal period of preterm, VLBW infants and to analyze differences in early growth parameters between SGA and AGA subjects.

\section{Methods}

A retrospective cohort study based on medical records was done in Perinatology Division of Dr. Sardjito General Hospital, Yogyakarta from 2011 until 2016. Subjects were infants with gestational age $<37$ weeks, birth weight of 1,000-1,499 g weighed within 1 hour after birth for Sardjito deliveries and 24 hours for out-of-Sardjito deliveries. Gestational age was determined by calculating Dubowitz score, or Ballard score for very ill infants. ${ }^{12}$ Twins, those who died during hospitalization, were discharged against medical advice, had gastrointestinal surgery, or syndromes were excluded from this study.

Sample size was calculated using an unpaired, categorical analysis formula, with 20\% proportion considered to be significantly different between the affected and not affected groups. Adequate intrauterine growth was based on Lubchenco table criteria. ${ }^{13}$ Subjects were subcategorized as SGA (birth weight $<10^{\text {th }}$ percentile) or AGA (birth weight between $10^{\text {th }}$ and $90^{\text {th }}$ percentiles), based on sex and gestational age. Recorded perinatal comorbidities, such as PDA, neonatal sepsis, respiratory distress, NEC, and anemia requiring transfusion were analyzed as possible predictors of postnatal growth failure. Echocardiography was done to assess for PDA. Neonatal sepsis was defined by fulfilling 4 of 7 clinical criteria (abnormal heart rate, abnormal respiration rate, lethargy, jaundice, feeding intolerance, thermoregulation instability, and abnormal laboratory finding). Respiratory distress was defined as needing mechanical ventilation in the first 24 hours, neonatal pneumonia, ventilator dependency of $>72$ hours, meconium aspiration syndrome, and/or oxygen dependence for more than 28 days. Necrotizing enterocolitis (NEC) was defined by the pertinent clinical symptoms and revealed by plain, abdominal $\mathrm{X}$-ray. Anemia was defined as low hemoglobin level which caused hemodynamic instability and needed packed red cell (PRC) transfusion. Growth failure was defined as discharge weight based on chronological age and sex of $<10^{\text {th }}$ percentile on the Fenton curve. ${ }^{8,13}$ Bivariate analysis with Chi-square test followed by multivariate analysis with logistic regression test were used to assess the main possible predictors of growth failure during hospitalization. Predictive factors from multivariate analysis with $\mathrm{P}$ values $<0.05$ were used for making mathematic models to calculate probability. Relative risk was calculated by comparing each probability based on clinical characteristics in preterm, VLBW infants. This study was approved by the Ethics Committee of Universitas Gadjah Mada Medical School, Yogyakarta.

\section{Results}

There were 636 preterm, VLBW infants during the 6-year study period in the Perinatology Ward of Dr. Sardjito General Hospital, of whom 238 were eligible for analysis and 398 were excluded (301 died, 43 twins, 39 discharged against medical advice, 3 syndromes, 12 incomplete medical records). Baseline characteristics of subjects are described in Table 1 .

The SGA subjects had median gestational age 3 weeks older than AGA infants. Both birth weight and discharge weight in SGA group were significantly lower than those of the AGA group (mean difference of birth weight was $42.2 \mathrm{~g}$ ). Differences in growth parameters between SGA and AGA subjects are described in Table 2.

Incidence of growth failure was $84.5 \%$. Only 
Noviyani Leksomono et al.: Predictors of early growth failure in preterm, very low birth weight infants during hospitalization

Table 1. Baseline characteristics and growth parameters of preterm, VLBW infants

\begin{tabular}{|c|c|}
\hline Characteristics and growth parameters & $\begin{array}{l}\text { Preterm VLBW } \\
\qquad(\mathrm{N}=238)\end{array}$ \\
\hline SGA, n (\%) & $120(50.4)$ \\
\hline Male sex, $\mathrm{n}(\%)$ & $122(51.3)$ \\
\hline $\begin{array}{l}\text { Gestational age, } \mathrm{n}(\%) \\
\quad<32 \text { weeks } \\
\quad \geq 32-36 \text { weeks }\end{array}$ & $\begin{array}{l}105(44,1) \\
133(55.9)\end{array}$ \\
\hline $\begin{array}{l}\text { Type of delivery, } \mathrm{n}(\%) \\
\text { Vaginal } \\
\text { C-section }\end{array}$ & $\begin{array}{r}92(38.7) \\
146(61.3)\end{array}$ \\
\hline Mean birth weight (SD), g & $1,271.7(138.6)$ \\
\hline Mean discharge weight (SD), g & $1,682.5(182.3)$ \\
\hline $\begin{array}{l}\text { Discharge weight, } \mathrm{n}(\%) \\
<3^{\text {rd }} \text { percentile } \\
\text { Between } 3^{\text {rd }} \text { and } 10^{\text {th }} \text { percentile } \\
\geq 10^{\text {th }} \text { percentile }\end{array}$ & $\begin{aligned} 183 & (76.9) \\
18 & (7.6) \\
37 & (15.5)\end{aligned}$ \\
\hline Median length of stay (range), days & $33(13-95)$ \\
\hline Neonatal asphyxia, n (\%) & $106(44.5)$ \\
\hline $\begin{array}{l}\text { Perinatal comorbidities } \\
\text { Neonatal sepsis, } \mathrm{n}(\%) \\
\text { Positive culture, n (\%) } \\
\text { PDA, n (\%) } \\
\text { Respiratory distress, n (\%) } \\
\text { NEC, } \mathrm{n}(\%) \\
\text { Anemia, } \mathrm{n}(\%)\end{array}$ & $\begin{array}{r}224(94.1) \\
108(48.2) \\
24(10.1) \\
136(57.1) \\
18(7.6) \\
109(45.8\end{array}$ \\
\hline $\begin{array}{l}\text { Maternal problems } \\
\text { Preeclampsia/eclampsia, n (\%) } \\
\text { Hypertension, n (\%) } \\
\text { HELLP/partial HELLP, n (\%) } \\
\text { Diabetes melitus,n (\%) } \\
\text { Cardiac problem, n (\%) }\end{array}$ & $\begin{array}{c}109(45.8) \\
67(28.2) \\
45(18.9) \\
4(1.7) \\
17(7.1)\end{array}$ \\
\hline Mean weight velocity (SD), g/kg/day & $16.9(5.3)$ \\
\hline $\begin{array}{l}\text { Median time to regain birth weight (range), } \\
\text { days }\end{array}$ & $11(3-42)$ \\
\hline $\begin{array}{l}\text { Median time to reach full feeding (range), } \\
\text { days }\end{array}$ & $16(5-57)$ \\
\hline $\begin{array}{l}\text { Median time to reach } 120 \mathrm{kcal} / \mathrm{kg} / \mathrm{day} \\
\text { (range), days }\end{array}$ & $20(8-53)$ \\
\hline
\end{tabular}

$1.7 \%$ of all SGA, preterm, VLBW subjects reached discharge weight $\geq 10$ th percentile, while the rest stayed in the $<3$ rd percentile of the Fenton growth curve according to their chronological age. Subjects without growth failure regained birth weight, reached full feeding, and reached $120 \mathrm{kcal} / \mathrm{kg} /$ day faster than subjects without growth failure. They also had significantly higher mean weight velocity than those with growth failure (Table 3).

Bivariate analysis followed by multivariate analysis was used to compare independent variables
(SGA and perinatal comorbidities) that may contribute to postnatal growth failure during hospitalization (Table 4). Logistic regression revealed that SGA and respiratory distress were the significant predictors of growth failure in preterm VLBW infants. Based on probability comparison from a mathematic model/y (using constant from logistic regression for predictive study), the relative risk was calculated using the following formula:

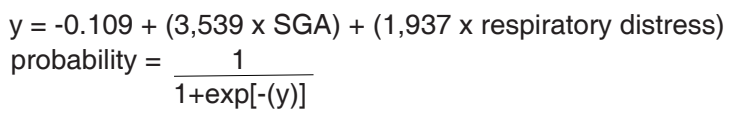

(SGA: Yes=score 1, No=score 0; respiratory distress: $Y$ es=score $1, \mathrm{No}=$ score 0 )

The relative risk of preterm, SGA, VLBW infants with respiratory distress suffering growth failure when they were discharged was 2.1 times higher than in AGA, VLBW infants without respiratory distress.

\section{Discussion}

In this study, 301 (47.3\%) infants died during hospitalization within 6 years period. Only $5 \%$ of SGA, VLBW infants with less than 32 weeks gestational age survived until discharge. The high mortality rate was caused by complex perinatal comorbidities and younger gestational age. Tsai et al. reported that the mortality rate of SGA, VLBW with less than 32 weeks gestational age was significantly increased (OR 1.89; $95 \%$ CI 1.39 to 2.58$).{ }^{15}$

Surviving preterm, VLBW infants who passed critical phase in early life created specific proportion. As expected, the AGA group was dominated by infants of 28 to 32 weeks gestational age, while the SGA group was predominantly infants of 34 to $<37$ weeks gestational age. This composition was similar to another Perinatology Unit/NICU of a tertiary hospital, with a high mortality rate $(50 \%)$ and median birth weight of $1,540 \mathrm{~g}$ in VLBW infants $>32$ weeks gestational age. ${ }^{13}$

The most common maternal problems in our study were preeclampsia/eclampsia and hypertension. These conditions are related to placental insufficiency that cause intrauterine growth retardation, such that the SGA proportion are higher than that of AGA. In the general population, SGA is at about $10-15 \%$, much 
Noviyani Leksomono et al.: Predictors of early growth failure in preterm, very low birth weight infants during hospitalization

Table 2. Differences in early growth parameters between SGA and AGA subjects

\begin{tabular}{lccc}
\hline Parameters & $\begin{array}{c}\text { SGA } \\
(\mathrm{n}=120)\end{array}$ & $\begin{array}{c}\text { AGA } \\
(\mathrm{n}=118)\end{array}$ & P value \\
\hline Median gestational age (range), weeks & $33(30-36)$ & $30(27-33)$ & 0.01 \\
Mean birth weight (SD), g & $1,250.76(143.22)$ & $1,292.96(130.93)$ & 0.02 \\
Male sex, $\mathrm{n}(\%)$ & $61(50.8)$ & $61(52.1)$ & 0.49 \\
Median time to regain birth weight (range), days & $11(3-42)$ & $12(3-35)$ & 0.18 \\
Mean weight velocity (SD), g/kg/day & $16.50(5.99)$ & $17.52(5.32)$ & 0.25 \\
Median time to reach full feeding (range), days & $16(6-38)$ & $16(5-57)$ & 0.49 \\
Median time to reach 120 kcal/kg/day (range), days & $20(8-51)$ & $21(9-53)$ & 0.43 \\
Mean discharge weight (SD), g & $1,642.52(133.25)$ & $1,723.05(214.46)$ & 0.01 \\
Median length of stay (range), days & $32(13-79)$ & $34(13-95)$ & 0.73 \\
\hline
\end{tabular}

Table 3. Comparison of growth parameters in subjects with and without postnatal growth failure

\begin{tabular}{lccl}
\hline Growth parameters & $\begin{array}{c}\text { With growth failure } \\
(\mathrm{n}=201)\end{array}$ & $\begin{array}{c}\text { Without growth failure } \\
(\mathrm{n}=37)\end{array}$ & P value \\
\hline Mean time to regain birth weight (SD), days & $12.6(6.2)$ & $10.2(3.9)$ & 0.04 \\
Mean time to reach full feeding (SD), days & $18.7(8.2)$ & $15.3(4.7)$ & 0.055 \\
Mean time to reach 120 kcal/kg/day (SD), days & $22.9(9.4)$ & $18.9(5.9)$ & 0.03 \\
Mean weight velocity (SD), g/kg/day & $16.5(5.4)$ & $18.8(4.7)$ & 0.02 \\
\hline
\end{tabular}

Table 4. Predictive factors of early postnatal growth failure in preterm, VLBW infants

\begin{tabular}{|c|c|c|c|c|c|}
\hline \multirow{3}{*}{$\begin{array}{l}\text { Predictor } \\
\text { factors }\end{array}$} & \multicolumn{5}{|c|}{ Growth failure $(n=201)$} \\
\hline & \multicolumn{3}{|c|}{ Bivariate analysis } & \multicolumn{2}{|c|}{ Multivariate analysis } \\
\hline & $\mathrm{n}(\%)$ & OR $(95 \% \mathrm{Cl})$ & $P$ value & adj OR $(95 \% \mathrm{Cl})$ & $P$ value \\
\hline SGA & $118(58.7)$ & $\begin{array}{c}24.88 \\
\text { (5.82 to } 106.31)\end{array}$ & 0.001 & $\begin{array}{c}34.44 \\
\text { (7.79 to } 152.4)\end{array}$ & 0.001 \\
\hline Male sex & $108(53.7)$ & $\begin{array}{c}1.91 \\
(0.93 \text { to } 3.92)\end{array}$ & 0.055 & $\begin{array}{c}1.89 \\
(0.81 \text { to } 4.42)\end{array}$ & 0.14 \\
\hline PDA & $22(10.9)$ & $\begin{array}{c}2.15 \\
(0.48 \text { to } 9.56)\end{array}$ & 0.24 & $\begin{array}{c}1.88 \\
\text { (0.35 to } 10.03)\end{array}$ & 0.46 \\
\hline Neonatal sepsis & $190(94.5)$ & $\begin{array}{c}1.52 \\
(0.40 \text { to } 5.75)\end{array}$ & 0.38 & & \\
\hline $\begin{array}{l}\text { Respiratory } \\
\text { distress }\end{array}$ & $126(62.7)$ & $\begin{array}{c}4.54 \\
(2.08 \text { to } 9.89)\end{array}$ & 0.001 & $\begin{array}{c}6.94 \\
\text { (2.93 to } 16.42)\end{array}$ & 0.001 \\
\hline Anemia & $93(46.3)$ & $\begin{array}{c}1.13 \\
(0.56 \text { to } 2.29)\end{array}$ & 0.44 & & \\
\hline NEC & $16(8.0)$ & $\begin{array}{c}1.51 \\
(0.33 \text { to } 6.88)\end{array}$ & 0.45 & & \\
\hline $\mathrm{T} 120>14$ days & $161(80.1)$ & $\begin{array}{c}0.78 \\
(0.30 \text { to } 1.99)\end{array}$ & 0.39 & & \\
\hline
\end{tabular}

lower than our findings. Our high SGA proportion may have been because there were many referral cases to our hospital, due to maternal and perinatal complications.

The most common perinatal comorbidity in this study was neonatal sepsis $(94.1 \%)$, much higher than studies by Lima et al. ${ }^{16}(4.6 \%)$ and Shan et al. $(56.8 \%) .{ }^{17}$ Neonatal sepsis is caused by the interaction of internal factor (immature immune system) and external factors, such as inappropriate infectious 
transmission/termination practices (deemed to be in part due to poor hand-washing compliance in the nursery, high room density, frequency of room fogging, and selection of definitive antibiotics.) In addition, a diagnosis of neonatal sepsis in this study required a minimum of 4 from 7 criteria. Blood culture was performed only in $73.9 \%$ of sepsis patients. About $40 \%$ of all neonatal sepsis cases had negative blood culture. These results are indicative of the difficulty of prescribing appropriate antibiotics due to the lack of a definitive cause of sepsis. Prolonged sepsis may affect infant growth rate during hospitalization.

In this study, subjects' mean weight velocity was 16.8 (SD 5.33) g/kg/day, which was similar to growth targets of NICUs worldwide. $1^{8}$ Mean weight velocity in our subjects was higher than a Brazilian study [9.3 (SD 2.3) $\mathrm{g} / \mathrm{kg} /$ day]. This result proved that Indonesian preterm VLBW infants had same potential growth rate as found in other developing country. ${ }^{19}$ Mean of weight velocity in the subgroup without growth failure was $2.3 \mathrm{~g} / \mathrm{kg} /$ day higher than the subgroup with growth velocity failure $(\mathrm{P}=0.015)$. Based on these findings, we have to evaluate weight velocity weekly from the time they regained their birth weight, so that we can recognize growth impairment earlier.

Median time to reach full feeding was 16 days for both SGA and AGA groups. A previous study reported that the mean time to reach full feeding in VLBW infants was 15 days. $2^{\circ}$ Median time to reach $120 \mathrm{kcal} / \mathrm{kg} /$ day in SGA and AGA was 20 and 21 days, respectively, similar to Anchieta et al., who reported the highest growth rate in the third week of life. ${ }^{21}$ There was no significant difference between time to regain birth weight, time to reach full feeding, or time to reach $120 \mathrm{kcal} / \mathrm{kg} /$ day between the SGA and AGA groups. This finding means that discharge weight was determined by adequate intrauterine growth and weight velocity in the early weeks of life.

The incidence of growth failure in this study $(84.5 \%)$ was much higher than in studies by Lima et al. ${ }^{16}(26 \%)$ and Marks et al. (10.6\%). ${ }^{22}$ This finding may have been due to the higher SGA proportion in our study than the previous ones, while growth failure was experienced mostly by SGA infants. Variations in growth failure incidence may also have been affected by study location, complexity of medical condition, gestational age, and applied nutritional management guidelines. ${ }^{23}$ In our center, nutritional practices for
SGA and AGA preterm, VLBW infants are not different.

Mean weight velocity of the SGA group was less lower than that of the AGA group $(\mathrm{P}=0.25)$. Ineffective energy utilization and energy deficit due to perinatal comorbidities in SGA infants are basic causes of growth impairment. In addition, basal metabolic rate in SGA is generally higher than in AGA infants. The minimal energy reserve in SGA infants is due to the thin layer of fat that increases heat loss and results in greater energy expenditure. ${ }^{24}$ Postnatal growth failure is due to a complex interaction of comorbidities which lead to energy expenditure and endocrine function abnormalities, central nervous system impairment and immaturity, as well as immature sucking and swallowing reflexes. Ultimately, inadequate nutrition and energy deficit during the first weeks of life are considered to be most responsible for postnatal growth failure. $^{23}$

Respiratory distress was a perinatal comorbidity that was significantly associated with postnatal growth failure during hospitalization. Infants with respiratory distress have trouble consuming liquids, including enteral feeding as their primary energy source. It also increases the basal metabolic rate, aggravating the total energy deficit in preterm, VLBW infants. ${ }^{20,23}$ Other perinatal comorbidities, such as neonatal sepsis, PDA, anemia, and NEC were not significantly associated with growth failure in preterm, VLBW infants in our study. This finding was contrast to a previous study that reported anemia requiring transfusion related with delayed time to regain. ${ }^{26}$ The lack of an association could have been due to an immediate hemoglobin correction to stabilize the hemodynamics at the time of diagnosis, hence, the growth parameter was just transiently impaired. In our study, the complexity and synergy of perinatal comorbidities caused a high incidence of growth failure, while single perinatal comorbidities were not significantly associated with growth failure.

The high incidence of postnatal growth failure may have also been influenced by low calorie intake during the transition period from parenteral to full enteral feeding. Based on our findings, calorie intake decreases about $10-20 \mathrm{kcal} /$ day during the transition period. Energy deficits during the transition period may only maintain the status quo or even cause decreased growth rate. Inadequate energy and protein intake 
Noviyani Leksomono et al.: Predictors of early growth failure in preterm, very low birth weight infants during hospitalization

during the transition period contribute to the risk of growth failure during hospitalization. ${ }^{27}$ The time interval from regaining birth weight until reaching full feeding and nutrition for growth at $120 \mathrm{kcal} / \mathrm{kg} / \mathrm{day}$ was longer in our subjects than in a previous study. ${ }^{28}$ Prolonged energy and calorie deficits in preterm, VLBW in that status quo interval (while they had already been ready for increasing body weight) cause higher growth failure in our study.

Other than SGA and respiratory distress, we need to study other factors that may contribute to growth failure in preterm, VLBW infants during hospitalization, such as early enteral feeding and monitoring the application of nutritional practices. Our study had several weakness as the retrospective design might have resulted in bias in data collection, and we only analyzed body weight to evaluate growth failure. Our study was the first in Indonesia to review detailed growth parameters in preterm, VLBW infants during early life. This study also reported on the difference in early growth parameters between SGA and AGA infants.

In conclusion, SGA and respiratory distress are significant predictors of early growth failure in preterm, VLBW infants during hospitalization. SGA infants grew less slower than AGA infants. These findings imply that low weight velocity in weekly monitoring was an appropriate warning sign of postnatal growth failure. We should optimize the interval between weight regain time, time to reach full feeding, and time to reach $120 \mathrm{kcal} / \mathrm{kg} /$ day, in order to prevent prolonged nutritional deficits. Early nutritional management targets in SGA, preterm, VLBW infants aim to maintain weight gain in parallel with the growth curve and prevent severe postnatal growth failure (discharge weight $<3^{\text {rd }}$ percentile).

\section{Conflict of Interest}

No conflict of interest.

\section{Funding acknowledgements}

The authors received no specific grant from any funding agency in the public, commercial, or not-for-profit sectors.

\section{References}

1. Bertino E, Di Nicola P, Giuliani F, Coscia A, Varalda A, Occhi L, et al. Evaluation of postnatal growth of preterm infants. J Matern Fetal Neonatal Med. 2011;24:9-11.

2. Namiiro FB, Mugalu J, McAdams RM, Ndeezi G. Poor birth weight recovery among low birth weight/preterm infants following hospital discharge in Kampala, Uganda. BMC Pregnancy Childbirth [Internet]. 2012;12:1-7.

3. Balitbang Kemenkes RI. Riset Kesehatan Dasar 2013. Jakarta; Kementrian Kesehatan RI 2013. p.1-10.

4. Horbar JD, Ehrenkranz RA, Badger GJ, Edwards EM, Morrow KA, Soll RF, et al. Weight growth velocity and postnatal growth failure in infants 501 to 1500 grams: 2000-2013. Pediatrics. 2015;136:e84-92.

5. Ehrenkranz RA, Younes N, Lemons PJA, Fanaroff AA, Donovan EF, Wright LL, et al. Longitudinal growth of hospitalized very low birth weight infants. Pediatrics. 1999;104:280-9.

6. Rover MMS, Viera CS, Silveira RC, Guimarães ATB, Grassiolli S. Risk factors associated with growth failure in the follow-up of very low birth weight newborns. J Pediatr (Rio J). 2016;92:307-13.

7. Committee on Nutrition. Nutritional needs of low birth weight infants. Pediatrics. 1985;75:976-86.

8. Abel DM. Actual and prescribed energy and protein intakes for very low birth weight infants: An observational study [dissertation]. Bloomington (IN): Indiana University; 2012.

9. Lubchenco LO, Hansman C, Edith B. Intrauterine growth in length and head circumference as estimatedfrom live births at gestational ages from 26 to 42 weeks. Pediatrics. 1966;37:403-8

10. Campos M, Reyes G, Garcia L. Comparison of postdischarge growth in adequate for gestational age and small for gestational age very low birthweight infants. Ethn Dis. 2008;18(suppl 2):S2118-22.

11. Obasa TO, Mohammed SS, Ernest SK, Mokuolu OA, Radmacher PG, Looney SW, et al. Extrauterine growth restriction occurring in babies with gestational ages equal to and less than 32 weeks managed at the University of Ilorin Teaching Hospital. J Med Med Sci. 2003;3:392-5.

12. McKee-Garrett TM. Postnatal assesment of gestational age. uptodate. 2018;

13. Lubchenco LO, Hansman C, Dressler M, Boyd E. Intrauterine growth as estimated from liveborn birth-weight data at 24 to 42weeksof gestation. Pediatrics. 1963;32:793-800.

14. Fenton TR, Kim JH, Secker D, Onis M De, Garza C, 
Noviyani Leksomono et al:: Predictors of early growth failure in preterm, very low birth weight infants during hospitalization

Victora C. A systematic review and meta-analysis to revise the Fenton growth chart for preterm infants. BMC Pediatr. 2013;13:59.

15. Tsai LY, Chen YL, Tsou KI, Mu SC. The impact of small for gestational age on neonatal outcome among very low birth weight infants. Pediatr Neonatol [Internet]. 2015;56(2):101-7. Available from: http://dx.doi. org/10.1016/j.pedneo.2014.07.007

16. Lima PAT, De Carvalho M, Da Costa ACC, Moreira MEL. Variables associated with extra uterine growth restriction in very low birth weight infants. J Pediatr (Rio J). 2014;90:22-7.

17. Shan HM, Cai W, Cao Y, Fang BH, Feng Y. Extrauterine growth retardation in premature infants in Shanghai: A multicenter retrospective review. Eur J Pediatr. 2009;168:1055-9.

18. Schanler RJ. Nutritional composition of human milk and preterm formula for the preterm infant. uptodate. 2017. [cited on 2017 May 13]. Available from: https://www.uptodate. com/contents/nutritional-composition-of-human-milk-andpreterm-formula-for-the-premature-infant.

19. Shakeel F, Napolitano A, Newkirk M, Harris JE, Ghazarian SR. Improving Clinical Outcomes of Very Low Birth Weight Infants by Early Standardized Nutritional Management. ICAN. 2015;7:328-37.

20. Tali S, Kabra N, Ahmed J, Dash S, Balasubramanian H, Avasthi B, et al. Effect of feeding scheduleon time toreach full feeds in ELBW and VLBW neonates: a randomized trial.
Perinatology. 2016;17:95-102.

21. Anchieta LM, Xavier CC, Colosimo EA. [Growth velocity of preterm appropriate for gestational age newborns]. J Pediatr [Internet]. 2004;80:417-24.

22. Marks K, Reichman B, Lusky A, Zmora E. Fetal growth and postnatal growth failure in very low birth weight infants. Acta Paediatr [Internet]. 2006;95:236-42.

23. $\mathrm{Su} \mathrm{BH}$. Optimizing nutrition in preterm infants. Pediatr Neonatol [Internet]. 2014;55:5-13. Available from: http:// dx.doi.org/10.1016/j.pedneo.2013.07.003

24. Yau KI, Chang MH. Growth and body compositionof preterm, small for gestational age infants at a postmenstrual age of 37-40 weeks. Early Hum Dev. 1993;33:117-31.

25. Goulart AL, Morais MB De, Kopelman BI. Impact of perinatal factors on growth deficits of preterm infants. Rev Assoc Med Bras. 2011;57:269-75.

26. Jeon GW, Sin JB. Risk factors of transfusion in anemia of very low birth weight infants. Yonsei Med J [Internet]. 2013;54:366-73.

27. Miller M, Vaidya R, Rastogi D, Bhutada A, Rastogi S. From parenteral to enteral nutrition: a nutrition-based approach for evaluating postnatal growth failure in preterm infants. J Parenter Enter Nutr. 2014;38:489-97.

28. Bertino E, Coscia A, Mombrò M, Boni L, Rossetti G, Fabris $\mathrm{C}$, et al. Postnatal weight increase and growth velocity of very low birthweight infants. Arch Dis Child Fetal Neonatal Ed [Internet]. 2006;91:F349-56. 